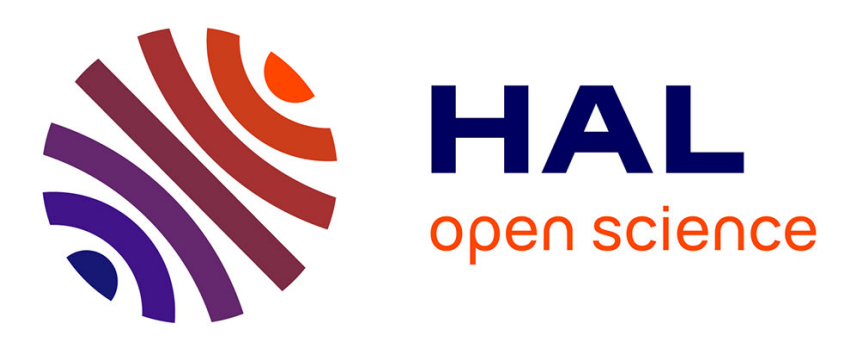

\title{
Nosocomial and community-acquired Acinetobacter infections
}

\author{
Marie-Laure Joly-Guillou
}

\section{To cite this version:}

Marie-Laure Joly-Guillou. Nosocomial and community-acquired Acinetobacter infections. Acinetobacter Biology Infections and Pathogenesis, Springer, pp.155-166, 2008, 10.1007/978-0-387-77944-7_9 . hal-03333608

\section{HAL Id: hal-03333608 \\ https://univ-angers.hal.science/hal-03333608}

Submitted on 7 Sep 2021

HAL is a multi-disciplinary open access archive for the deposit and dissemination of scientific research documents, whether they are published or not. The documents may come from teaching and research institutions in France or abroad, or from public or private research centers.
L'archive ouverte pluridisciplinaire HAL, est destinée au dépôt et à la diffusion de documents scientifiques de niveau recherche, publiés ou non, émanant des établissements d'enseignement et de recherche français ou étrangers, des laboratoires publics ou privés. 


\title{
Nosocomial and Community-acquired Acinetobacter Infections
}

\author{
Marie Laure Joly-Guillou
}

\section{Introduction}

Members of the genus Acinetobacter are involved in a wide spectrum of infections. Although this organism is mainly associated with nosocomial infections, these bacteria have been recently shown involved in community-acquired infection. Over 1,000 published papers refer to "infections by antibiotic resistant Acinetobacter in the international literature." This opportunistic commensal bacterium was initially considered a relatively low-grade pathogen and frequently ignored until the 1960s, even when isolated from clinical samples. However, marked improvement in culture techniques in the last 30 years increased awareness of infections due to Acinetobacter. Prior to the 1970s, nosocomial infections by this organism were mainly detected after surgical procedures or in the urinary tract from patients hospitalized in intensive care units (ICU), but since the 1980s, acinetobacters were found rapidly spread among ICU patients. At the present time, this bacterium represents about 9-10\% of all nosocomial infections, but the majority are due to respiratory tract infection. The origin of such infections is known to be both endogenous and exogenous, and the introduction of single-use disposable patient items is now known to limit endogenous infection. Nevertheless, transmission of the bacteria by the hands of hospital staff is now known to be an important risk factor for patient colonization. Of the many different microbial species isolated from various environments, Acinetobacter baumannii is known to be the most frequently involved in human infections. Although the reservoirs outside of hospital environments are not clearly defined, community acquired infection and infection related to war or earthquakes have been recognized and may be due to presence of these microbes in the soil. The severity of such infection by this bacterium depends on the site of infection and the degree of a patient's immune competence related to underlying disease. Acinetobacter may cause mild to severe illness and can be fatal. However, a consensus whether this organism is indeed highly pathogenic is not established since this organism is 
thought to be mainly a low-grade pathogen. It is likely that increased pathogenesis by this microbe involves numerous factors, including virulence factors that are not yet clear. However, there is now increased interest in this pathogen the last 30 years (Livermore, 2003), since recognition of antibiotic multiresistant strains, including pan resistance, emerged in an outbreak in a clinical unit (Del Mar et al., 2005; Fierobe et al., 2001; Mah et al., 2001; Rello, 2003; Simor et al., 2002; Smolyakov et al., 2003). In hot and humid areas such as the tropics, Acinetobacter infections are usually community acquired, in general bacteremias, or primary infections (Anstey et al., 2002).

\section{Mortality and Morbidity}

The clinical impact of Acinetobacter infections in terms of morbidity and mortality is highly variable. Since the $1980 \mathrm{~s}$, A. baumannii has been found to spread rapidly among ICU patients. Recorded incidences of nosocomial infection vary from about 4-8.2 \% in Spain in the period 1990-1997 (Vaque et al., 1999) or 9\% in 1995 in Europe (Vincent et al., 1995). These bacteria have been compared to Staphylococcus aureus resistance to methicillin (MRSA) and even designated "Gram negative MRSA" (Rello, 2003). This epidemiological spread of Acinetobacter is similar to MRSA, and has an impact on morbidity and mortality similar to coagulase-negative staphylococci (Rello and Diaz, 2003). However, the incidence of Acinetobacter bacteremia is estimated to be ten fold less than $S$. aureus (1.5\% as compared to $14 \%$, respectively, Wisplinghoff et al., 2000). Nevertheless, some authors believe clinicians should be alert to the emergence of this potentially difficult and dangerous organism responsible for infectious outbreaks, which may cause severe problems (Kaul et al., 1996; Theaker et al., 2003). Recently published reports concerning overall mortality rates vary from 20 to nearly $60 \%$. However, there have only been a few studies of mortality rates using multivariant analysis. Although this type of study should be further performed, mortality rates in a few studies have been often shown to be between $10 \%$ and $20 \%$ (Blot et al., 2003; Poutanen et al., 1997; Wisplinghoff et al., 2000). The species A. baumannii appears to be of the greatest clinical importance. Nevertheless, there is a close relationship between $A$. baumannii complex species (A. baumannii, calcoaceticus sp. 3 and the sp 13 of Tenberg and Ursing). These isolates are more resistant to antibiotics and responsible for numerous outbreaks throughout the world (Bergogne-Bérézin et al., 1996). The A. baumannii complex is considered different from other species, similar to differences between $S$. aureus and coagulase-negative staphylococci. Other Acinetobacter species are not frequently involved in human infection outbreaks, but are generally isolated from patients suffering from severe underlying disease. Furthermore, clinical laboratories sometimes have difficulties differentiating other Acinetobacter species from A. baumannii, since conventional tests are usually insufficient for accurate identification. 


\section{Nosocomial Bacteremia}

Bacteremia caused by Acinetobacter is currently one of the infections with highest mortality in hospitals. A survey of the health protection agency in England showed that patients with bacteremia were more than 50 years of age and the majority male. Among these patients, $5 \%$ were hospitalized in general wards and 54\% in ICUs (Wisplinghoff et al., 2000). Risk factors were defined in many studies and found similar to other opportunistic bacteria (Blot et al., 2003; Vaque et al., 1999; Poutanen et al., 1997). Sepsis and/or septic shock were observed in one study in 19\% of bacteremias (Valero et al., 2001). However, this observation stressed the major pathogenicity of only a few strains. Although, the overall mortality rates were about $40 \%$, mortality of about $8 \%$ was reported in one survey related to inappropriate therapy (Wisplinghoff et al., 2000). Mixed infections are frequent in Acinetobacter bacteremia and this may be related to bacterial synergy. A. baumannii infection generally represents about $10-15 \%$ of Acinetobacter bacteremia isolates. However, in another survey, Valero et al. (2001) identified a high rate of non-A. baumannii bacteremia. These species were preferentially isolated from patients hospitalized in hematology wards, rather than the majority of $A$. baumannii isolated from ICU patients.

\section{Nosocomial Pneumoniae}

Before the 1970s, Acinetobacter infections were mainly detected in postsurgical and urinary/renal disease patients. Since these bacteria were isolated mainly from patients hospitalized in surgical or medical wards, significant improvement in culture techniques the last 30 years provided a fuller view of Acinetobacter infection frequency (Fagon et al., 1996; Garnacho et al., 2003). McDonald et al. (1999) reported that from 1976 to 1990, the incidence of nosocomial pneumoniae due to Acinetobacter increased from less than 1 to no more than $6 \%$. At the present time, these organisms from ventilator-associated pneumonia are known to be markedly increasing. Infection rates of $30-75 \%$ have been reported for nosocomial pulmonary infection due to Acinetobacter species, with the highest rates reported in ventilator-dependent patients (Cardenosa Cendrero 1999). The use of specific microscopic and laboratory techniques has demonstrated the increasing role of $A$. baumannii in such nosocomial pneumonia (Chastre et al., 1996), and the distribution as well as the prevalence of these bacteria were observed in a large survey (Rello 1999). Incidence varied from one center to another, with an overall incidence of $8 \%$ in the SCOPE virulence system. Acinetobacter species were found present in only 24 or 49 USA hospitals participating (Wisplinghoff et al., 2000). From the century surveillance program of 144 Latin American countries, Gales et al. (2002) found Acinetobacter species in only 7 countries. The epidemiology of nosocomial 
respiratory colonization and/or infection with $A$. baumannii is known to be complex due to co-existence of epidemics with unrelated sporadic cases caused by different strains (Chastre, 2003).

\section{Wound and Burn Infections}

A. baumannii is a common cause of nosocomial infection in burn patient populations. Infections caused by these bacteria are less severe than that caused by other organisms. In a recent report, burn patients with Acinetobacter infection had more severe burns and co-morbidities. However, on multivariant analysis, infection with $A$. baumannii was not found associated with mortality (Albrecht et al., 2006). Outbreaks due to this organism have been described in burn units and many of the infections have been associated with antibiotic multiresistant strains. A persistent outbreak is often related to persistent contamination of the hospital environment (Simor et al., 2002). In 1985, Sherertz and Sullivan described a persistent outbreak due to contamination of patient mattresses.

\section{Infective Endocarditis}

Endocarditis due to Acinetobacter is relatively rare, but with high mortality and reported mainly in hospitalized patients with previous heart disease factors (Valero et al., 1999). Rarely reported, acinetobacters also constitute one of several causes of early prosthetic valve endocarditis. A diffuse red bacterial maculopapullar may be encountered (Olut et al., 2005). Some cases of prosthetic vale endocarditis due to Acinetobacter lwoffi have also been described (Starakis et al., 2006).

\section{Neonatal Nosocomial Infections}

Neonatal sepsis is the major cause of death in newborns despite sophisticated neonatal intensive care. There have been only a few reports of Acinetobacter infections or outbreaks in neonates. A. baumannii is responsible for the majority of neonatal sepsis (greater than 72 hrs of age) with a mortality rate of $11 \%$ compared to early onset sepsis due to group B streptococcus. Infections have been described in ventilated infants with a birth weight less than $1500 \mathrm{~g}$ and hospitalized for more than 7 days (Mehr et al., 2002; Jiang et al., 2004; Von Dolinger et al., 2005). The intestinal flora of a neonate is considered the reservoir of the organism, and the rate of intestinal carriage of these bacteria is a variable risk factor. 


\section{Meningitis}

Acinetobacter is a rare cause of meningitidis. Sporadic cases have been reported following neurosurgical procedures (Chen et al., 2005). In 1989, an outbreak of Acinetobacter meningitis was described in a group of children with leukemia (Kelkar et al., 1989) following administration of intrathecal methotrexate and due to inappropriately sterilized needles. Three of the children died as a result of meningitis. Risk factors include the presence of a continuous connection between the ventricles and the external environment, a ventriculostomy, a CSF fistula, presence of an indwelling ventricular catheter for more than 5 days, and the use of antimicrobial agent. Metan et al. (2007) in Turkey reported a wide prevalence of multiresistant Acinetobacter causing meningitis in neurosurgical patients. The surveillance of local pathogens in neurosurgical wards should guide the selection of empirical therapy and an effective infection control program.

\section{Pathogenesis, Dissemination, and Outbreaks}

In clinical practice, Acinetobacter infections are closely associated with surgery or artificial devices, and colonization precedes infection. For patients to become infected, various risk factors are necessary for pathogenesis. This is one explanation for the increasing incidence of these infections, especially in ICUs, because of multiple manipulations due to surgical practice. The use of endotracheal tubes, intravascular, ventricular, or urinary catheters often leads to opportunistic bacteria colonizing the site. In this regard, the presence and duration of invasive procedures, as well as exposure to wide-spectrum antibiotics have been identified as risk factors in many studies for acquisition of Acinetobacter (Koeleman et al., 2001). Because Acinetobacter is transmitted via the hands of the staff, the care workload "omega score" could represent a good marker for determination of these risk factors (Saulnier et al., 2001). Bacterial overgrowth in the stomach is another pathway that may be involved in development of nosocomial pneumonia or bacteremia. This may occur under conditions of diminution of acid secretion often observed in ICU patients. Acinetobacter readily multiply under these conditions (Cardenosa et al., 1999). A. baumannii is responsible for occasional but sudden outbreaks, which are usually unexpected and then difficult to control. The local circumstances of clinical units and the environment determine the type of infection, dissemination, and risk of outbreak. Acinetobacter, considered a low-grade pathogen, can remain on or in an individual without causing illness. Dissemination via the hand of the staff often remains unnoticed or undetected (Wang et al., 2003). Infections are less numerous than by another pathogen such as $S$. aureus. In a clinical unit, the ratio of colonized to infected patients may be as high as 2 to 1 for methicillin-resistant $S$. aureus vs.10 to 1 for Acinetobacter. Patients with 
infection manifestations are likely to be the "tip of the iceberg" and dissemination is likely to be the "underground of a mushroom bed" (Bayuga et al., 2002). When infections due to Acinetobacter emerge, the number of colonized patients is probably already high and the alert to prevent an outbreak given too late (Carbonne et al., 2005). During an outbreak, all environment surfaces can be a reservoir. Acinetobacter readily survive, especially in ICUs, and this can be the case from days to weeks even in dry conditions. Under such conditions, even health care workers may be colonized on various sites with Acinetobacter (Wagenvort et al., 2002).

\section{Wartime and Earthquake Infections}

Acinetobacter has been found responsible for infections in various particular situations. After the Marmara earthquake in Northwest Turkey in 1999, 220 of 630 victims were hospitalized and $18.6 \%$ had nosocomial infections. Among these, $31.2 \%$ of the isolates were $A$. baumannii and two were pan-resistant strains. The prevalence of Acinetobacter infections before the earthquake was of $7.3 \%$ in the same hospital ICU without identification of multiresistant strains (Oncül et al., 2002). The literature from the Vietnam, Iran-Iraq, and Gulf wars identified multidrug resistant Acinetobacter as a war-zone community acquired pathogen, both colonizing and infecting casualties (Mitchell et al., 2007; Tong, 1972). Early infections observed in soldiers were more often soft tissue or surgical wound infections. Osteomyelitis caused by Acinetobacter occurred, but less frequently reported (Davis et al., 2005). During January 1, 2002-August 31, 2004, military health officials identified 102 patients by blood culture that grew $A$. baumannii in medical facilities treating service members injured in Afghanistan and the Iraq/Kuwait region. The number of patients with Acinetobacter blood infections in 2003 and 2004 exceeded those reported in previous years. These findings suggest environmental contamination of wounds as a potential source (CDC, 2004).

\section{Community-acquired Infections}

More than 100 cases of community-acquired pneumonia have been described since the 1980s. Meningitis, cellulitis, or primary bacteremia have been noticed rarely. Acute pneumonia is the most frequent community-acquired infection. Patients with acute pneumonia generally have a history of alcohol abuse, diabetes, cancer, or broncho-pulmonary disease. The literature often described a fulminating course of infection and septic shock in about $30 \%$ of cases, as well as respiratory failure. Patients frequently have productive sputum and hemoptysis. The high mortality rate has been related to the patient background and delay in appropriate therapy. In a recent study, Leung et al. (2006) found that 
$32 \%$ of patients with pneumonia have bacteraemia. Generally, bacteremia has been described mainly in tropical developing countries such as New Guinea, Thailand, or even Australia (Anstey et al., 2002; Wang et al., 2002). A few cases occur in temperate countries such as Spain, France, or the United States (Megarbane et al., 2000; Salas et al., 2003). Cases are more prevalent in warm and humid months, even in temperate regions (McDonald et al., 1999). Increasing colonization may probably be linked to perspiration and overuse of broadspectrum antibiotics in a population. A few studies have shown the presence of Acinetobacter in body lice, fleas, or ticks and propose their role as vectors in transmission of community-acquired infections, particularly among the homeless (La Scola et al., 2001).

\section{Pathogenicity and Virulence}

In the past, Acinetobacter was considered an organism with low virulence. The occurrence of fulminating community-acquired Acinetobacter pneumonia indicates that this bacterium can be also highly pathogenic and cause invasive disease. Studies on virulence factors are still at an elementary stage. Nonspecific adherence factors such as fimbriae have been described in Acinetobacter (Bergogne-Bérézin et al., 1996; Rathinavelu et al., 2003). Under iron-deficient conditions, bacterial growth can be accompanied by production of receptors and iron-regulated catechol siderophores, which favor bacterial growth and expression of virulence factors (Goel and Kapil, 2001). Acinetobacter lipopolysacharide, similar to those of other Gram-negative bacilli, is responsible for lethal toxicity in mice and the positivity of the amebocyte-lysate test (endotoxin detection) during Acinetobacter septicemia. This lipopolysacharide is involved in resistance to complement in human serum and acts in synergy with the capsular exopolysaccharide.

Complement appears to play a role in the bactericidal activity of human serum. A relationship between the degree of resistance of Gram-negative bacteria isolated from bacteremic patients to the lytic activity of complement in vitro and their ability to penetrate into human fluids has been described. Lipopolysacharide and capsular polysaccharide are both involved in this phenomenon. Capsular polysaccharide is known to block complement access to the microbial cell wall and prevent the triggering of the alternate pathway of complement activation, demonstrated in experimental models of Gram-negative infections. Exopolysaccharide production by pathogenic bacteria is a major virulence factor and thought to protect bacteria from host defenses and lethal for mice and cytotoxic for phagocytic cells. About 30\% of strains produce exopolysaccharide. This production has been studied in A. calcoaceticus BD4, a strain that synthesizes a thick exopolysaccharide capsule composed of rhamnose, mannose, glucose, and glucuronic acid. In experimental studies, exopolysaccharide-producing strains of $A$. calcoaceticus were shown to be more 
pathogenic than nonproducing strains, especially in polymicrobial infections with other species of higher virulence (Obana, 1986). Quorum sensing is a widespread regulatory mechanism among Gram-negative bacteria like Pseudomonas aeruginosa. Four different quorum-sensing signal molecules capable of activating $\mathrm{N}$-acylhomoserine-lactone biosensors have been found in Acinetobacter clinical strains, with maximal activity reached at the stationary growth phase (Gonzalez et al., 2001). Quorum-sensing might be a central mechanism for auto-induction of multiple virulence factors in an opportunistic pathogen like Acinetobacter and should be studied for clinical implications.

\section{Conclusion and Perspectives}

Many parameters, such as host factors, bacterial burden, and strain virulence, may have important roles in promoting clinical infection in colonized patients. Acinetobacter is often multiresistant to antibiotics and thus, identifying factors influencing virulence would permit identifying low-virulent strains against which antibiotic therapy could be avoided. In contrast, identification of highly virulent colonizing strains in the respiratory tract could lead to greater prophylactic use of antibiotic treatment of high-risk patients. Careful hand washing with soap and water, as well as alcohol-based hand sanitizers, should be vigorously encouraged.

\section{References}

Albrecht, M.A., Griffith, M.E., Murray, C.K., Chung, K.K., Horvath, E.E., Ward, J.A., Hospenthal, D.R., Holcomb, J.B., Wolf, S.E. 2006. Impact of Acinetobacter infection on the mortality of burn patients. J Am Coll Surg. 203:546-550.

Anstey, N.M., Currie, B.J., Hassell, M., Palmer, D., Dwyer, B., Seifert, H. 2002. Communityacquired bacteremic Acinetobacter pneumonia in tropical Australia is caused by diverse strains of Acinetobacter baumannii, with carriage in the throat in at-risk groups. J. Clin. Microbiol. 40:685-686.

Bayuga, S., Zeana, C., Sahni, J., Della-Latta, P., El-Sadr, W., Larson, E. 2002. Prevalence and antimicrobial patterns of Acinetobacter baumannii on hands and nares of hospital personnel and patients: the iceberg phenomenon again. Heart Lung. 31:382-390.

Bergogne-Berezin, E., Joly-Guillou, M.L., Towner, K.J. 1996. Acinetobacter, microbiology, epidemiology, infections, management. CRC Press, FL.

Blot, S., Vandewoude, K., Colardyn, F. 2003. Nosocomial bacteremia involving Acinetobacter baumannii in critically ill patients; a matched cohort study. Int Care Med. 29:471-475.

Carbonne, A., Naas, T., Blanckaert, K., Couzigou, C., Cattoen, C., Chagnon, J.L., Nordmann, P., Astagneau, P. 2005. Investigation of a nosocomial outbreak of extendedspectrum B-lactamase VEB-1-producing isolates of Acinetobacter baumannii in a hospital setting. J Hosp Infect. 60:14-18.

Cardenosa Cendrero, J.A., Sole-Violan, J., Bordez Benitez, A., Noguera Catalan, J., Arroyo Fernandez, J., Saavedra Santana, P., Rodriguez de Castro F. 1999. Role of different routes of tracheal colonization in the development of pneumonia in patients receiving mechanical ventilation. Chest. 116:462-470. 
Centers for Disease Control and Prevention (CDC). 2002-2004. Acinetobacter baumannii infections among patients at military medical facilities treating injured U.S. service members. MMWR Morb Mortal Wkly Rep. 53:1063-1066.

Chastre, J. 2003. Infections due to Acinetobacter baumannii in the ICU. Semin Respir Crit Care Med. 24:69-78.

Chastre, J., Trouillet, J.L., Vuagnat, A., Joly-Guillou, M.L. 1996. Nosocomial pneumonia caused by Acinetobacter spp. In Bergogne-Berezin, E., Joly-Guillou, M.L., Towner, K.J. (eds.), Acinetobacter, Microbiology, Epidemiology, Infections, Management. Florida: CRC Press.

Chen, S.F., Chang, W.W., Chuang, Y.C., Tsaï, H.H., Tsaï, N.W., Chang, H.W., Lee, P.Y., Chien, C.C., Huang, C.R., Young, T.G. 2005. Adult Acinetobacter meningitis and its comparison with non Acinetobacter Gram negative bacterial meningitis. ACTA neurol Taïwan. 14:131-137.

Davis, K.A., Moran, K.A., McAllister, C.K., Gray, P.J. 2005. Multidrug-resistant Acinetobacter extremity infections in soldiers. Emerging Infect Dis. 11:1218-1224.

Del Mar, C., Thomas, M., Cartelle, M., Pertega, S., Beceiro, A., Llinares, P., Canle, D., Molina, F., Villanueva, R., Cisneros, J.M., Bou, G. 2005. Hospital outbreak caused by a carbanepen-resistant strain of Acinetobacter baumannii: patient prognosis and risk-factors for colonisation and infection. Clin Microbiol Infect. 11:540-6.

Fagon, J.Y., Chastre, J., Domart, Y., Trouillet, J.L., Gibert, C. 1996. Mortality due to ventilator-associated pneumonia or colonization with Pseudomonas or Acinetobacter species. Assessment by quantitative culture of samples obtained by a protected specimen brush. Clin Infect Dis. 23:538-542.

Fierobe, L., Lucet, J.C., Decre, D., Muller-Seryies, C., Deleuze, A., Joly-Guillou, M.L., Mantz, J., Desmont, J.M. 2001. An outbreak of imipenem-resistant Acinetobacter baumannii in critically ill surgical patients. Infect Control Hosp Epidemiol. 22:35-40.

Gales, A.C., Sader, H.S., Jones, R.N. 2002. Respiratory tract pathogens isolated from patients hospitalized with suspected pneumonia in Latin America: frequency of occurrence and antimicrobial susceptibility profile: results from the SENTRY Antimicrobial Surveillance Program (1997-2000). Diagn Microbiol Infect Dis. 44:301-11.

Garnacho, J., Sole-Violan, J., Sa-Borges, M., Diaz, E., Rello, J. 2003. Clinical impact of pneumonia caused by Acinetobacter baumannii in intubated patient: a matched cohort study. Crit Care Med. 10:2478-2482.

Goel, V.K., Kapil, A. 2001. Monoclonal antibodies against the iron regulated outer membrane Proteins of Acinetobacter baumannii are bactericidal. BMC Microbiol. 1: 16-24

Gonzalez, R.H., Nusblat, A., Nudel, B.C. 2001. Detection and characterization of quorum sensing signal molecules in Acinetobacter strains. Microbiol Res. 155:271-277.

Jiang, J.H., Chiu, N.C., Huang, F.Y., Kao, H.A., Hsu, C.H., Hung, H.Y., Chang, J.H., Peng, C.C. 2004. Neonatal sepsis in the neonatal intensive care unit: characteristics of early versus late onset. J Microbiol Immunol Infect. 37:301-306.

Kaul, R., Burt, J.A., Cork, L., Dedier, H., Garcia, M., Kennedy, C., Brunton Krajden, M., Conly, J. 1996. Investigation of a multiyear multiple critical care unit outbreak due to relatively drug-sensitive Acinetobacter baumannii: risk factors and attributable mortality. J Infect Dis. 174:1279-1287.

Kelkar, R., Gordon, S.M., Giri, N., Rao, K., Ramakrishnan, G., Saikia, T., Nair, C.N., Kurkure, P.A., Pai, S.K., Jarvis, W.R. and Advani, S.H. 1989. Epidemic iatrogenic Acinetobacter spp. meningitis following administration of intrathecal methotrexate. J Hosp Infect. 14: 233-243

Koeleman, J.G.M., Van Der Bijl, M.W., Stoof, J., Vanderbroucke-Grauls, C.M.J.E., Savelkoul, P.H.M. 2001. Antibiotic resistance is a major risk factor for epidemic behavior of Acinetobacter baumannii. Infect Control Hosp Epidemiol. 22:284-288.

La Scola, B., Fournier, P.E., Brouqui, P., Raoult, D. 2001. Detection and culture of Bartonella quintana, Serratia marscesens, and Acinetobacter spp. from decontaminted human body lice. J Clin Microbiol. 39:1707-1709. 
Leung, W.S., Chu, C.M., Tsang, K.Y., Lo, F.H., Lo, K.F., Ho, P.L. 2006. Fulminant community acquired Acinetobacter baumannii pneumonia as a distinct clinical syndrome. Chest. 129: 102-109.

Livermore, D.M. 2003. The threat from the pink corner. Ann Med Int. 35:226-234.

Mah, M.W., Memish, Z.A., Cunningham, G., Bannatyne, R.M. 2001. Outbreak of Acinetobacter baumannii in an intensive care unit associated with tracheostomy. Am J Infect Control. 29:284-288.

McDonald, L.C., Banerjee, S.N., Jarvis, W.R. 1999. Seasonal variation of Acinetobacter infections: 1987-1996. Nosocomial Infections Surveillance System. Clin Infect Dis. 29:1133-1137.

Megarbane, B., Bruneel, F., Bedos, J.P., Wolff, M., Regnier, B. 2000. Acinetobacter baumannii community-acquired pneumonia in a patient with HIV infection. Presse Med. 29:788-789.

Mehr, S.S., Sadowsky, J.L., Doyle, L.W., Carr, J. 2002. Sepsis in neonatal intensive care in the late 1990s. J Paediatr Child Health. 38:246-251.

Metan, G., Alp, E., Aygen, B., Sumerkan, B. 2007. Carbapenem-resistant Acinetobacter baumannii: an emerging threat for patients with post-neurosurgical meningitidis. Int $\mathrm{J}$ Antimicrob Agents. 29:112-116.

Mitchell, A.E., Siviz, L.B., Black, R.E. Editors. 2007. Gulf War and Health: Volume 5. Infectious Diseases. Washington DC: The National Academies Press.

Obana, Y. 1986. Pathogenic significance of Acinetobacter calcoaceticus: analysis of experimental infection in mice. Microbiol Immunol. 30:645-657.

Olut, A.I., Erkek, E. 2005. Early prosthetic valve endocarditis due to Acinetobacter baumannii: a case report and brief review of the literature. Scand J Infect Dis. 37:919-921.

Oncül, O., Keskin, O., Acar, H.V., Kucukardali, Y., Evrenkaya, R., Atasoyu, E.M., Top, C., Nalbant, S., Ozkan, S., Emekdas, G., Cavuslu, S., Us, M.H., Pahsa, A., Gokben, M. 2002. Hospital-acquired infections following the 1999 Marmara earthquake. J Hosp Infect. 51:47-51.

Poutanen, S.M., Louie, M., Simor, A.E. 1997. Risk factors, clinical features and outcome of Acinetobacter bacteremia in adults. Eur J Clin Microbiol Infect Dis. 16: 737-740.

Rathinavelu, S., Zavros, Y., Merchant, J.L. 2003. Acinetobacter lwoffii infection and gastritis. Microbes Infect. 5:651-657.

Rello, J. 1999. Acinetobacter baumannii infections in the ICU: customization is the key. Chest. 115:1226-1229.

Rello, J., Diaz, E. 2003. Acinetobacter baumannii: a threat for ICU. Intensive Care Med. 29:350-351.

Salas Coronas, J., Cabezas Fernandez, T., Alvarez-Ossorio Garcia de Soria, R., Diez Garcia, F. 2003. Community-acquired Acinetobacter baumannii pneumonia. Rev Clin Esp. 203:284-286.

Saulnier, F.F., Hubert, H., Onimus, T.M., Beague, S., Nseir, S., Grandbastien, B., Renault, C.Y., Idzik, M., Erb, M.P., Durocher, A.V. 2001. Assessing excess nurse work load generated by multi-resistant nosocomial bacteria in intensive care. Infect Control Hosp Epidemiol. 22:273-278.

Sherertz, R.J., Sullivan, M.L. 1985. An outbreak of infections with Acinetobacter calcoaceticus in burn patients: contamination of patients' mattresses. J Infect Dis. 151:252-258.

Simor, A.E., Lee, M., Vearncombe, M., Jones-Paul, L., Barry, C., Gomez, M., Fish, J.S., Cartotto, R.C., Palmer, R., Louie, M. 2002. An outbreak due to multi-resistant Acinetobacter baumannii in a burn unit: risk factors for acquisition and management. Infec Control Hosp Epidemiol. 23:261-267.

Smolyakov, R., Borer, A., Riesenberg, K., Schlaeffler, F., Alkan, M., Porath, A., Rimar, D., Almog, Y., Gilad, J. 2003. Nosocomial multi-drug resistant Acinetobacter baumannii bloodstream infection: risk factor and outcome with ampicillin-sulbactam treatment. J Hosp Infect. 54:32-38. 
Starakis, I., Blikas, A., Siagris, D., Marangos, M., Karatza, C., Bassaris, H. 2006. Prosthetic valve endocarditis caused by Acinetobacter lwoffi: a case report and Review. Cardiol Rev. 14:45-49.

Theaker, C., Azadian, B., Soni, N. 2003. The impact of Acinetobacter baumannii in the intensive care unit. Anaesthesia. 58:271-274.

Tong, M.J. 1972. Septic complications of war wounds. JAMA. 219:1044-1047.

Valero, C., Farinas, M.C., Garcia Palomo, D., Mazarrasa, J.C., Gonzalèz Macias, J. 1999. Endocarditis due to Acinetobacter lwoffi on native mitral valve. Int $\mathrm{J}$ Cardiology. 69:37-99.

Valero, C., Garcia Palomo, J.D., Mattoras, P., Fernandez-Mazarrasa, C., GonzalesFernandez, C., Farinas, M.C. 2001. Acinetobacter bacteraemia in a teaching hospital, 1989-1998. Eur J Int Med. 12:425-429.

Vaque, J., Rossello, J., Arribas, J.L. 1999. Prevalence of nosocomial infections in Spain: EPINE study 1990-1997. EPINE Working Group. J Hosp Infect. 43:S105-S111.

Vincent, J.L., Bihari, D.J., Suter, P.M., Bruining, H.A., White, J., Nicholas-Chanoine, M.H. 1995. The prevalence of nosocomial infection in intensive care units in Europe. Results of the European Prevalence of infection in intensive care (EPIC) study. EPIC International Advisory Committee. JAMA. 274:639-644.

Von Dolinger De Brito, D., Oliveira, E.J., Abdallah, V.O., Da Costa Darina, A.L., Filho, P.P. 2005. An outbreak of Acinetobacter baumannii septicemia in a neonatal intensive care unit of a university hospital in Brazil. Braz J Infect Dis. 9:301-309.

Wagenvort, J.H.T., De Brauwer, E.I.G.B., Toenbreker, H.M.J., Van Der Linden, C.J. 2002. Epidemic Acinetobacter baumannii strain with MRSA-like behaviour carried by healthcare staff. Eur J Clin microbiol Infect Dis. 21:326-327.

Wang, J.T., McDonald, L.C., Chang, S.C., Ho, M. 2002. Community-acquired Acinetobacter baumannii bacteremia in adult patients in Taiwan. J Clin Microbiol. 40:1526-1529.

Wang, S.H., Sheng, W.H., Chang, Y.Y., Wang, L.H., Lin, H.C., Chen, M.L., Pan, H.J., Ko, W.J., Chang, S.C., Lin, F.Y. 2003. Healthcare-associated outbreak due to pan-drug resistant Acinetobacter baumannii in a surgical intensive care unit. $\mathrm{J}$ Hosp Infect. 53:97-102.

Wisplinghoff, H., Edmond, M.B., Pfaller, M.A., Jones, R.N., Wenzel, R.P., Seifert, H. 2000. Nosocomial blood stream infections caused by Acinetobacter species in United States Hospitals: Clinical features, molecular epidemiology, and antimicrobial susceptibility. Clin Infect Dis. 31:690-697. 